Sharif University of Technology
Scientia Iranica
Transactions E: Industrial Engineering
http://scientiairanica.sharif.edu

\title{
A bi-level programming model for decentralized manufacturer-distributer supply chain considering cooperative advertising
}

\author{
O. Amirtaheri, M. Zandieh*, and B. Dorri \\ Department of Industrial Management, Management and Accounting Faculty, Shahid Beheshti University, G.C., Tehran, Iran.
}

Received 6 April 2016; received in revised form 21 November 2016; accepted 27 December 2016

KEYWORDS
Production-
distribution supply
chain;
Cooperative
advertising;
Stackelberg game;
Bi-level programming;
Genetic algorithm.

\section{Introduction}

Generally, there are two approaches towards decisionmaking in a supply chain: centralized and decentralized. In a centralized supply chain, a single decisionmaker or principal firm with access to adequate information within the supply chain along with enough power to make decisions delineates the policies for all members of the chain. In such a case, different members cooperate with each other based on the declared policies. Mathematical programming models have been used to address such problems in the literature [1].

A supply chain is often composed of independent

\footnotetext{
*. Corresponding author. Tel.: +982129905215

E-mail address: m_zandieh@sbu.ac.ir (M. Zandieh)
}

organizations and economic entities. In spite of the advantages associated with integrated decision-making, firms often do not tend to follow the decisions made for all members and try to optimize their own objectives rather than those of the entire system [2]. Therefore, a decentralized supply chain is seen to be a more practical and realistic model for many real-world problems.

In the literature, Hierarchical Decision Making (HDM) has been used to model decentralized supply chain management problems. In such a system, the upper-level member (leader) makes a decision at first and then the lower-level member (follower) determines their optimal policies based on the decision made by the leader. Assuming a complete set of information to be available about the decision-making approach of the follower, the leader will be able to anticipate the response of the follower based on which they can adjust their decisions. Hierarchical decision-making 
process is closely related to the economic problem of Stackelberg in the field of Game Theory, introduced by Von Stackelberg [3].

Hierarchical programming is a mathematical framework of Stackelberg games within which multiple optimization problems in different levels are simultaneously taken into account. A special case of the problem with two levels is called bi-level problem or bi-level programming problem [4]. A bi-level programming problem is a mathematical program with an optimization problem in the constraints.

Each decision-maker (the leader and the follower) attempts to determine the decision variables under their control to optimize their own objective function regardless of the one of the other; however, the decisions made by each member influence the available choices and payoffs of the other decision-maker. Thus, the leader will be able to affect the follower without having a full control over them, while being simultaneously affected by the follower's behavior.

The current research aims at using bi-level programming for modeling of the relationship between a manufacturer and a distributor under decentralized management with their objective being the maximization of the profit via meeting the demands generated in different markets. The markets are different in terms of size, geographic location, price elasticity of demand, and response to advertisement. We assume each market's demand is a function of selling price, local advertising expenditure, and global advertising expenditure.

In order to boost the markets' demands, the distributor undertakes a given cost to conduct local advertising within each market. Being undertaken to motivate the customer to make a purchase in shorttime, such expenditures may be spent in the form of catalogues or promotional gifts, free product sample, price discounts, incentive plans, etc. in a given market. With direct but short-time effect, these advertising efforts increase the demand across the corresponding markets [5].

On the other hand, the manufacturer may, in turn, set a budget for global advertising within the target markets. Normally broadcasted at national level with their scopes beyond any specific market, global advertisements work toward forming a long-resisting recognized image of the manufacturer's brand and logo inside the customers' minds. Participation in general and specialized exhibitions as well as TV and Radio advertisements is an example of this type of advertising. Although global advertising may promote a product's fame and popularity, it may not necessarily increase real demands raised by a consumer $[6,7]$. As such, the manufacturer tends to directly affect market demand via implementing cooperative advertising approach [5].

Cooperative advertising is seen to be among those topics intensely investigated in the literature during the recent years [8]. This concept represents a financial agreement between the manufacturer and the distributor (retailer) to share advertising costs based on which the manufacturer undertakes part of local advertising expenditure (participation rate) incurred by the distributor [4].

Following the research directions suggested by [8], this paper aims at simultaneously determining the pricing, advertising, inventory, and allocation policies in a production-distribution supply chain using bilevel programming while considering cooperative advertising. Manufacturer's decisions include wholesale price, production (replenishment) interval, global advertising expenditure, and the participation rate in local advertising expenditures. On the other side, the distributor, as the second member of the chain, makes decisions on selling price, local advertising expenditure, and allocation of warehouses' capacities to markets' demands.

Since bi-level programming model, even in its simplest form (i.e., with linear objective functions and constraints), is NP-hard [9], a hierarchical genetic algorithm is developed to tackle each model. In addition to the GAs, an exhaustive grid search is applied for validation purposes.

The rest of the paper is organized as follows. In the next section, we review the related literature. In Section 3, a bi-level programming model is developed for each of the two power scenarios of a Stackelberg game. In the first model, the manufacturer is assumed to be the leader with the distributor being the follower (manufacturer-Stackelberg) while the opposite case (distributor-Stackelberg) is investigated in the second model. In Section 4, a hierarchical genetic algorithm is developed to tackle each of the bi-level programming models. In Section 5, computational experiments are carried out using the collected data from an automotive spare parts supply chain and the validity of the proposed GAs is shown by adopting an exhaustive grid search algorithm. Furthermore, the gained profit by each member as well as that of the entire system is compared under each power scenario. Finally, conclusions are drawn and future research directions are introduced in Section 6 .

\section{Literature review}

Numerous researches have studied the interaction between a manufacturer (supplier/seller) and a retailer (distributer/buyer) as two members of supply chain within a Stackelberg game framework. We consider the general settings of the supply chains and models, which are used in the related articles, and compare them in Table 1.

Authors often have their focus on one or several 
Table 1. Comparison of the general settings of the current paper and related studies.

\begin{tabular}{|c|c|c|c|c|c|c|c|c|c|c|c|c|c|}
\hline \multirow[t]{2}{*}{ Paper } & \multicolumn{4}{|c|}{$\begin{array}{l}\text { Decision } \\
\text { variables }\end{array}$} & \multirow{2}{*}{$\begin{array}{l}\text { Price } \\
\text { effect }\end{array}$} & \multirow{2}{*}{$\begin{array}{c}\text { Advertising } \\
\text { effect }\end{array}$} & \multicolumn{3}{|c|}{ Advertising } & \multirow{2}{*}{ 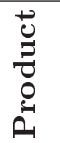 } & \multirow{2}{*}{ 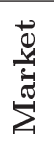 } & \multirow{2}{*}{$\begin{array}{c}\text { No. of } \\
\text { constraints }\end{array}$} & \multirow{2}{*}{$\begin{array}{l}\text { Solution } \\
\text { approach }\end{array}$} \\
\hline & $P$ & $A$ & $I$ & $T$ & & & $L$ & $G$ & Co & & & & \\
\hline$[10,39]$ & & $*$ & & & & $\alpha-\beta \cdot a^{-\gamma} \cdot A^{-\delta}$ & $*$ & $*$ & $*$ & 1 & 1 & - & $\mathrm{BI}$ \\
\hline$[13]$ & & $*$ & & & & $\alpha-\beta \cdot a^{-\gamma} \cdot A^{-\delta}$ & $*$ & $*$ & $*$ & 1 & 1 & 2 & BI \\
\hline$[15]$ & $*$ & $*$ & & & $\left(p / p_{0}\right)^{-e}$ & $\alpha-\beta \cdot a^{-\gamma} \cdot A^{-\delta}$ & $*$ & * & $*$ & 1 & 1 & - & BI \\
\hline [20] & $*$ & $*$ & & & $(\alpha-\beta \cdot p)^{1 / v}$ & $n^{1} \cdot \sqrt{A}+n^{2} \cdot \sqrt{a}$ & $*$ & $*$ & $*$ & 1 & 1 & - & BI \\
\hline$[27,28]$ & $*$ & $*$ & $*$ & & $k \cdot p^{-\alpha}$ & $a^{\beta}$ & $*$ & & $*$ & 1 & 1 & - & BI \\
\hline [21] & $*$ & $*$ & & & $k \cdot p^{-\alpha}$ & $a^{\beta}$ & $*$ & & $*$ & 1 & 1 & - & BI \\
\hline$[22,23,40]$ & $*$ & $*$ & & & $\alpha-\beta . p$ & $n^{1} \cdot \sqrt{A}+n^{2} \cdot \sqrt{a}$ & $*$ & $*$ & $*$ & 1 & 1 & - & BI \\
\hline [11] & & $*$ & & & & $\left(\alpha-\beta \cdot a^{-\gamma} \cdot A^{-\delta}\right) \cdot \sqrt{g}$ & $*$ & $*$ & $*$ & 1 & 1 & - & BI \\
\hline [19] & $*$ & $*$ & & & $(\alpha-\beta \cdot p)^{1 / v}$ & $n^{1} \cdot \sqrt{A}+n^{2} \cdot \sqrt{a}$ & $*$ & $*$ & $*$ & 1 & 1 & - & BI \\
\hline$[16]$ & $*$ & $*$ & & & $p^{-e}$ & $\alpha-\beta \cdot a^{-\gamma} \cdot A^{-\delta}$ & $*$ & $*$ & $*$ & 1 & 1 & - & BI \\
\hline$[41]$ & $*$ & $*$ & & & $1-\beta_{1} \cdot p-\beta_{2} \cdot p^{\prime}$ & $n^{1} \cdot \sqrt{A}+n^{2} \cdot \sqrt{a}$ & $*$ & $*$ & $*$ & 2 & 1 & - & BI \\
\hline$[12]$ & & $*$ & & & & $\alpha-\beta_{1} \cdot a^{-\gamma}-\beta_{2} A^{-\delta}$ & $*$ & $*$ & $*$ & 1 & 1 & - & BI \\
\hline$[17]$ & $*$ & $*$ & & & $\alpha-\beta . p$ & $\alpha-\beta \cdot a^{-\gamma} \cdot A^{-\delta}$ & $*$ & $*$ & $*$ & 1 & 1 & - & BI \\
\hline$[18]$ & $*$ & $*$ & & & $\alpha-\beta . p$ & $n^{1} \cdot \sqrt{A}+n^{2} \cdot \sqrt{a}$ & $*$ & $*$ & $*$ & 1 & 1 & - & BI \\
\hline$[14]$ & & $*$ & & & & $n^{1} \cdot \sqrt{A}+n^{2} \cdot \sqrt{a}$ & $*$ & $*$ & $*$ & 1 & 1 & - & BI \\
\hline [25] & $*$ & & $*$ & & $\alpha-\beta . p$ & & & & & $M$ & 1 & $>3 N$ & BLP \\
\hline$[26]$ & $*$ & $*$ & $*$ & & $k \cdot p^{-\alpha}$ & $a^{\beta}$ & $*$ & & & M & 1 & 2 & BLP \\
\hline [24] & * & & $*$ & & $k \cdot p^{-\alpha}$ & & & & & 1 & 1 & 2 & BI \\
\hline$[40]$ & * & $*$ & & & $\alpha-\beta_{1} \cdot p+\beta_{2} \cdot p^{\prime}$ & $n^{1} \cdot \sqrt{A}+n^{2} \cdot \sqrt{a}-n^{3} \cdot \sqrt{a^{\prime}}$ & $*$ & $*$ & $*$ & 1 & 1 & - & BI \\
\hline $\begin{array}{l}\text { Proposed } \\
\text { model }\end{array}$ & * & $*$ & $*$ & $*$ & $(1-\alpha \cdot p)^{1 / v}$ & $n_{k}^{1} \cdot \sqrt{A}+n_{k}^{2} \cdot \sqrt{a}$ & $*$ & $*$ & $*$ & 1 & $M$ & $>I . J+2 J+K$ & BLP \\
\hline \multicolumn{14}{|c|}{$\alpha, \beta, \beta_{1}, \beta_{2}, \gamma, \delta, \tau, e, k, v, n^{1}, n^{2}>0$} \\
\hline \multicolumn{14}{|c|}{$a$ : Local advertising expenditure; } \\
\hline \multirow{3}{*}{\multicolumn{6}{|c|}{$\begin{array}{l}\text { A: Global advertising expenditure; } \\
p_{0} \text { : Manufacturer Suggested Retail Price (MSRP); } \\
G \text { : Global advertising; }\end{array}$}} & \multicolumn{5}{|c|}{$p$ : Retail price; } & \multicolumn{3}{|c|}{$p^{\prime}:$ Retail price of second retailer; } \\
\hline & & & & & & \multicolumn{5}{|c|}{$g$ : Reputation of the manufacturer; } & \multicolumn{3}{|c|}{$L:$ Local advertising; } \\
\hline & & & & & & \multicolumn{5}{|c|}{ Co: Co-operative advertising; } & \multicolumn{3}{|c|}{$M:$ Multi-product/market; } \\
\hline \multicolumn{5}{|c|}{$N$ : Number of products; } & & \multirow{2}{*}{\multicolumn{5}{|c|}{$\begin{array}{l}\text { I: Number of transportation cost levels; } \\
\text { BI: Backward Induction; }\end{array}$}} & \multirow{2}{*}{\multicolumn{3}{|c|}{$\begin{array}{l}J: \text { Number of warehouses; } \\
\text { BLP: Bi-Level Programming. }\end{array}$}} \\
\hline \multicolumn{5}{|c|}{$K$ : Number of markets $(k$} & $=1,2, \cdots, K)$ & & & & & & & & \\
\hline
\end{tabular}

aspects of the decisions to be made by supply chain members. From the second column of Table 1, we can see that the pricing and advertising policies have been used in most of the researches as a prominent mechanism for supply chain coordination.

Some authors refer to the different effects of local and global advertising on demand and study the cooperative advertising programs in supply chain coordination [10-14].

Furthermore, there are several studies that investigate the simultaneous determination of advertising and pricing. Yue et al. [15] study the issue of cooperative advertisement in a production-distribution supply chain in which the demand is sensitive to the price and the manufacturer offers price discounts to the distributor. Szmerekovsky and Zhang [16] investigate the issue of pricing and determination of advertising policy in a bi-level supply chain where the demand de- pends on the retail price and advertising expenditure. Xie et al. $[17,18]$ further extend this study and compare cooperative scenario with the two previously mentioned scenarios in which no cooperation is assumed between the manufacturer and the retailer. SeyedEsfahani et al. [19] investigate cooperative advertisement in a bilevel supply chain considering a more comprehensive demand function under four power scenarios: equal power, manufacturer-Stackelberg, retailer-Stackelberg, and cooperation among the members; the results are then compared. Aust and Buscher [20], Haifang et al. [21], Karray [22], and Kunter [23] are among the other papers that study the simultaneous effects of advertising and pricing policies.

Similarly, many researches have considered how to integrate pricing policies into inventory management decisions. Yugang et al. [24] study the decisions associated with pricing and ordering interval in a 
supply chain consisting of a distributor and a number of retailers. Mokhlesian and Zegordi [25] applied bilevel programming to coordinate pricing and inventory decisions in a two-stage supply chain consisting of one manufacturer and multiple retailers. A hybrid of genetic algorithm and local search method has been proposed to tackle the non-linear bi-level programming model.

Early works have mainly focused on integrating different decision aspects and developing more comprehensive models. Naeimi Sadigh et al. [26] determine pricing, inventory, and advertising policies in a multiple-product supply chain. In their work, manufacturer and retailer spend expenses for advertising. The problem is solved in manufacturer-Stackelberg and retailer-Stackelberg forms and the results are compared. Esmaeili et al. [27] propose several game models of seller-buyer relationship to optimize pricing and lot sizing decisions as well as participation in local advertising expenditures. Esmaeili and Zeephongsekul [28] develop several models for seller-buyer supply chain management problem with an asymmetric information structure. Their models incorporate the pricing, advertising, and lot sizing decisions.

As the simultaneous analysis of more than one aspect provides insight into the interdependencies of the decision variables, we incorporate the allocation policy into other three decision aspects (pricing, advertising, and inventory) by placing a distributer on the second echelon that possesses several warehouses with different capacities and geographical locations. Therefore, the decision about the allocation of warehouses' capacities to markets' demands, in a way that total transportation cost is minimized, can also be made along with pricing, advertising, and inventory decisions.

Among the most important distinctive features of the articles is the underlying demand function, which relates consumer demand to pricing and advertising decisions. The second and third columns of Table 1 indicate the effects of price and advertising expenditures on demand, respectively. The total demand function is made by multiplication of the two effects. In an attempt to extend the previous demand functions, Seyed Esfahani et al. [19] propose a comprehensive nonlinear structure for price demand function, $(\alpha-\beta . p)^{1 / v}$, where the new parameter $v$ controls the demand curve's shape in order to obtain a linear, convex, or concave function and make a better adjustment to the actual market properties. Inspired by their work, we use a similar form for price demand function, $(1-\alpha \cdot p)^{1 / v}$, in this paper. As for the advertising effect, we apply the square root form of advertising demand function proposed by $[14,18-20,22,23]$ and adapt it to a supply chain with $K$ different markets $\left(n_{k}^{1} \cdot \sqrt{A}+n_{k}^{2} \cdot \sqrt{a} ; k=\right.$ $1,2, \cdots, K)$.

Among the articles that have studied the effects of local and global advertising expenditures on demand, there are some researches that consider cooperative advertising program. In this paper, we follow a similar approach and assume that manufacturer and distributer undertake global and local advertising expenditures, respectively, and manufacturer participates in a portion of total expenditure incurred by distributer for local advertising in different markets.

Concerning the number of products and markets, one may observe that most authors consider a single product to be sold in a single market. In this paper, we develop a supply chain model in which $K$ different markets, in terms of size, price elasticity of demand, and response to global and local advertising expenditures, are considered.

The next criteria refer to the constraints of the models' formulation. A predominant number of related researches do not incorporate any constraint to their models, while a few articles consider two or more. The structure of the model proposed in this paper includes several warehouses and markets as well as decision variables for allocating markets' demands to warehouses' capacities. Thus, numerous constraints are considered to appropriately define the model.

Lastly, we consider the solution approach which is used in order to determine the channel members' optimal decisions. As explained in Section 1, decentralized supply chain problems are closely related to the Stackelberg game problem in game theory. Stackelberg game describes a sequential process, where one player acts as a leader and first sets their decision. Then, in the second step, the follower tries to find their best decision within the framework set by the leader. This equilibrium is calculated via Backward Induction (BI) method: The follower's response function, which is determined by setting the first order derivative(s) to zero and solving the resulting equations for the follower's decision variables, has to be inserted into the leader's profit function before calculating the first order derivatives [8]. The underlying logic of $\mathrm{BI}$ is based on determining the first derivative(s) of profit function for both leader and follower problems. Thus, any constraint has to be analyzed separately and then incorporated into the main calculations.

This reveals that BI, as an exact method, will lose its efficiency as the numbers of decision variables and constraints increase and ultimately fail due to considerable complexity of calculus, i.e. incorporating more decision variables generate more partial derivatives (equations) and handling more constraints needs complex analysis, which may not reach a solution.

As stated in Section 1, BLPP is a mathematical framework of Stackelberg game in which an optimization problem (follower) is embedded in another optimization problem (leader). This structure provides an appropriate form to include several decision variables 
and constraints. To tackle the complexity of BLPP, approximate solution methods including meta-heuristic algorithms are developed by the researchers.

From the last column of Table 1, we can recognize that BI is applied for the Stackelberg problems with no, or very few, constraints and limited number of decision variables while BLPP is applied in more complicated problems such as $[25,26]$. This is the main reason for applying BLPP in the current research.

To summarize, in this paper, we extend the previous studies by incorporating numerous decision variables and constraints into a decentralized manufacturer-distributer supply chain and developing two bi-level programming models to simultaneously determine the optimal policies of the channel members in terms of pricing, inventory, advertising, and demand allocation.

\section{Problem description}

Consider a bi-level supply chain including one manufacturer and one distributor. The manufacturer wholesales the product to his exclusive distributor at a wholesale unit price $(w)$; applying a retail profit ratio $(r)$, the distributor sells the goods from its warehouses to different markets. The distributer possess $J$ warehouses with given capacities $\left(b_{j} ; j=1,2, \cdots, J\right)$ and different geographic locations at various distances from the markets. On the other hand, it is assumed that there are $K$ different markets in terms of size, price elasticity of demand, and the response to global and local advertising efforts. Figure 1 depicts the structure of the proposed manufacturer-distributor supply chain.

According to the assumptions made by $[15,17]$, the demand function of each market can be considered as follows:

$$
\begin{aligned}
& D_{k}\left(p, a_{k}, A\right)=z_{k} \cdot g_{k}(p) \cdot h_{k}\left(a_{k}, A\right) ; \\
& k=1, \cdots, K \\
& p=w \cdot(1+r),
\end{aligned}
$$

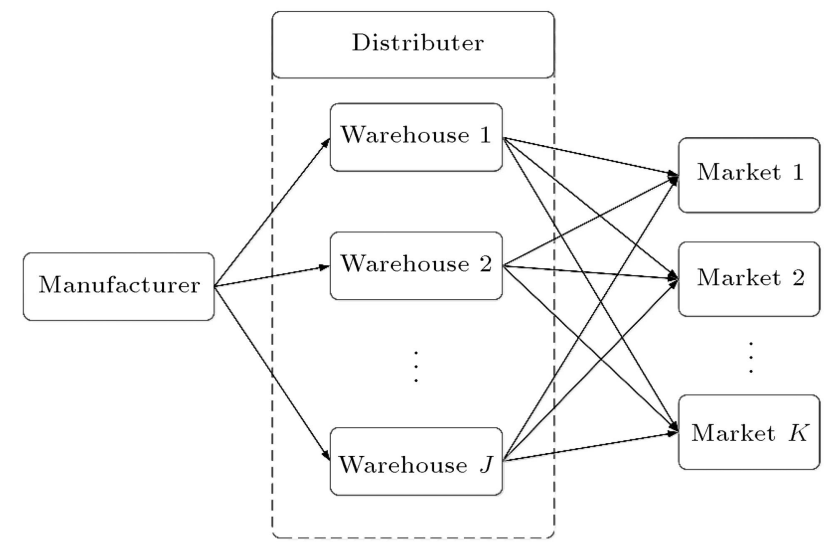

Figure 1. Manufacturer-distributor supply chain . where $z_{k}$ denotes the size of the $k$ th market, and functions $g_{k}(p)$ and $h_{k}\left(a_{k}, A\right)$ reflect the effects of selling price $(p)$, local advertising cost in the $k$ th market $\left(a_{k}\right)$, and global advertising cost $(A)$ on the market's demand.

Unlike a common assumption in many studies where the demand is a linear function of the price $[29,18]$, in this research, inspired by the concept of price elasticity of demand as in the study conducted by [19], a nonlinear function is considered to determine the relationship between the demand of each market and the selling price:

$$
g_{k}(p)=\left(1-\alpha_{k} \cdot p\right)^{1 / v_{k}} ; \quad k=1, \cdots, K,
$$

where $\alpha_{k}$ is a positive constant and $v_{k}$ is the shape factor of the demand curve in the $k$ th market. Values of $v_{k}<1, v_{k}=1$, and $v_{k}>1$ yield convex, linear, and concave demand function, respectively. The specific demand curve for each market can be incorporated into the model (in terms of its convex, concave, or linear nature) by adjusting the parameter $v_{k}$ so as to simultaneously study various consumer behaviors encompassed by a single general demand function. It is obvious that the condition $p \leq \min _{k=1, \cdots, K}\left\{1 / \alpha_{k}\right\}$ should be verified to avoid negative demand.

The function proposed by [18] is used to model advertising effect:

$$
h_{k}\left(a_{k}, A\right)=n_{k}^{1} \sqrt{A}+n_{k}^{2} \sqrt{a_{k}} ; \quad k=1, \cdots, K,
$$

where $n_{k}^{1}$ and $n_{k}^{2}$ are positive constants that reflect the effect of global and local advertising on the demand of $k$ th market, respectively. This approach is followed by other researchers as well $[14,19]$.

The function $h_{k}$ is strictly increasing and concave in $A$ and $a_{k}\left(\frac{\partial h_{k}}{\partial A}>0, \frac{\partial h_{k}}{\partial a_{k}}>0, \frac{\partial^{2} h_{k}}{\partial A^{2}}<0\right.$ and $\frac{\partial^{2} h_{k}}{\partial a_{k}^{2}}<$ $0 ; k=1,2, \cdots, K)$. This means that as local or global advertising expenditures increase, the resulting earnings follow a continuously decreasing trend. In the literature, such a concept is referred to as advertising saturation effect [30]. Based on the above explanations, the demand function would be the following:

$$
\begin{aligned}
D_{k} & =z_{k}\left(1-\alpha_{k} w(1+r)\right)^{1 / v_{k}}\left[n_{k}^{1} \sqrt{A}+n_{k}^{2} \sqrt{a_{k}} ;\right. \\
k & =1,2, \cdots, K .
\end{aligned}
$$

It is assumed that total demand $\left(D_{0}=\sum_{k=1}^{K} D_{k}\right)$ is completely covered by the distributor and the manufacturer. For this purpose, total induced demands by pricing and advertising policies shall exceed neither total capacity of the distributor warehouses nor the production capacity of the manufacturer $(G)$. Therefore, we have:

$$
D_{0}=\sum_{k=1}^{K} D_{k} \leq \min \left\{\sum_{j=1}^{J} b_{j}, G\right\} .
$$


In this research, inventory holding cost incurred by the manufacturer and each warehouses of the distributor are separately addressed. It is assumed that the manufacturer produces total demand of markets $\left(D_{0}\right)$ within lots of $Q_{0}$ units and delivers each lot to the warehouses based on their demand shares. Denoting the production (replenishment) interval as $T$ and the demand of $j$ th warehouse as $d_{j}$, the manufacturer delivers $Q_{0}=D_{0} . T$ units of product to the distributor's warehouses in each interval. The demand share of each warehouse from the production lot is calculated as $Q_{j}=d_{j} / D_{0} ;(j=1, \cdots, J)$. Assuming two warehouses, the inventory levels of the manufacturer as well as distributor warehouses are shown in Figure 2.

When it comes to product distribution, one of the significant expenditures is the transportation cost. Considering the fact that real-world supplying centers are normally far from the demanding ones, it is very important to calculate and incorporate such costs into the profit function for the distributor. Two types of product handling costs are considered in this research:

- Type 1: Transportation cost from the manufacturer stock to any of the distributor's warehouses;

- Type 2: Transportation cost from the distributor's warehouse to any of the markets.

In addition, it is assumed that, based on the agreement achieved between the manufacturer and the distributor, the delivery place of the products is manufacturer's stock. Therefore, both types of transportation cost will be incurred by the distributor.

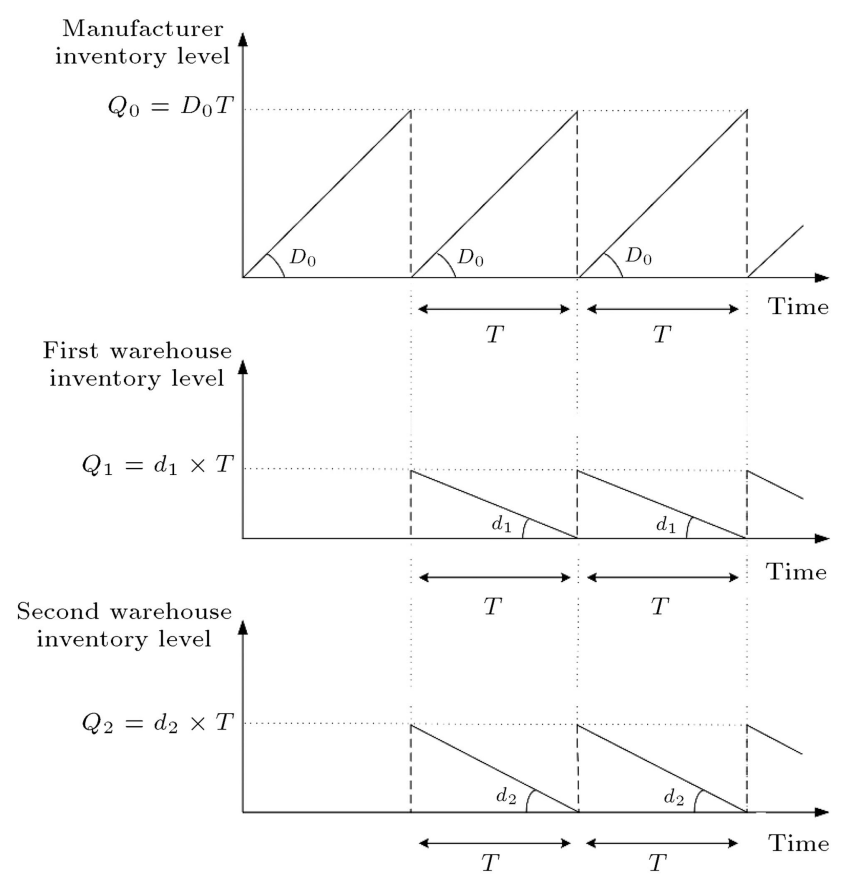

Figure 2. Inventory levels of the manufacturer and distributor warehouses.
In each replenishment cycle, the manufacturer delivers $Q_{j}$ product units to the distributor's $j$ th warehouse. Therefore, Type 1 transportation cost can be assumed to be a function of lot size $\left(Q_{j}\right)$ (see Figure 3).

Indicator variable, $y_{i}^{j}$, can be defined to model Type 1 transportation cost as follows:

$$
y_{i}^{j}= \begin{cases}1 ; & \text { if } q_{i-1} \leq Q_{j}<q_{i} \\ 0 ; & \text { Otherwise }\end{cases}
$$

Assuming that all distributor's warehouses follow the same pattern as Type 1 transportation cost, the following constraints must always be fulfilled to achieve a feasible solution:

$$
\begin{aligned}
& q_{i-1} \cdot y_{i}^{j} \leq Q_{j}<q_{i} \cdot y_{i}^{j}+M \cdot\left(1-y_{i}^{j}\right) \\
& i=1, \cdots, I, \quad j=1, \cdots, J, \quad q_{0}=0, \\
& \sum_{i=1}^{I} y_{i}^{j}=1 ; \quad j=1, \cdots, J,
\end{aligned}
$$

where $M$ denotes an extremely large positive constant. As the transportation is repeated in every replenishment cycle, the total Type 1 transportation cost for the distributor's $j$ th warehouse can be calculated as follows:

$$
L_{j}^{1}=\frac{1}{T} \cdot \sum_{i=1}^{I} s_{i} y_{i}^{j} ; \quad j=1, \cdots, J .
$$

On the other hand, the distributor is incurred by $c_{j k}$ units of Type 2 transportation cost as they transfer one unit of product from $j$ th warehouse to the $k$ th market. Such a cost can be seen as function of the distance of the warehouse from the desired market. Assuming a total of $x_{j k}$ products to be carried from the distributor's $j$ th warehouse to the $k$ th market within the planning interval, total Type 2 transportation cost for the distributor's $j$ th warehouse $\left(L_{j}^{2}\right)$ can be expressed as follows:

$$
L_{j}^{2}=\sum_{k=1}^{K} c_{j k} \cdot x_{j k} ; \quad j=1, \cdots, J .
$$

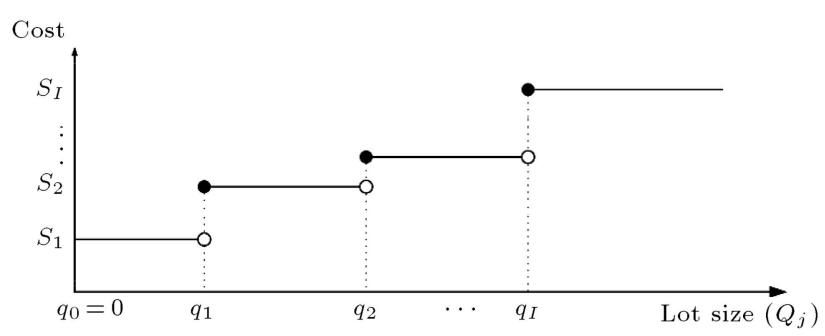

Figure 3. Levels of Type 1 transportation cost. 
The problem of minimization of Type 2 transportation cost is equal to an assignment problem in which supply centers are the distributor's warehouses and demand ones are the markets:

$$
\min \sum_{j=1}^{J} \sum_{k=1}^{K} c_{j k} x_{j k},
$$

S.t.

$$
\begin{aligned}
& \sum_{k=1}^{K} x_{j k} \leq b_{j} ; \quad j=1, \cdots, J, \\
& \sum_{j=1}^{J} x_{j k}=D_{k} ; \quad k=1, \cdots, K, \quad x_{j k} \geq 0 .
\end{aligned}
$$

In the above optimization problem, the first constraint ensures that total product shipped from the distributor's $j$ th warehouse to different markets will not exceed the warehouse capacity. In addition, total product units delivered from the distributor's warehouses to the $k$ th market should be equal to the demand raised by that market; this is guaranteed by the second constraint.

Table 2 reports the list of decision variables in the described manufacturer-distributer supply chain problem. We assume that the manufacturer decides on wholesale price, global advertising cost, participation rate in local advertising cost, and production (replenishment) interval for all warehouses. On the other side, distributer controls retail profit ratio, local advertising cost in each market, number of products to be delivered

\begin{tabular}{|c|c|}
\hline \multicolumn{2}{|c|}{ Variables controlled by manufacturer } \\
\hline$w$ & Wholesale price \\
\hline$A$ & Global advertising cost \\
\hline$T$ & Production (replenishment) interval \\
\hline$\theta$ & Participation rate in local advertising cost \\
\hline \multicolumn{2}{|c|}{ Variables controlled by distributer } \\
\hline$r$ & Retail profit ratio \\
\hline$a_{k}$ & $\begin{array}{l}\text { Local advertising cost in the kth market } \\
(k=1,2, \cdots, K)\end{array}$ \\
\hline$x_{j k}$ & $\begin{array}{l}\text { Number of product units to be shipped } \\
\text { from the distributor's } j \text { th warehouse to the } \\
k \text { th market }(j=1,2, \cdots, J, k=1,2, \cdots, K)\end{array}$ \\
\hline$y_{i}^{j}$ & $\begin{array}{l}\text { Indicator variable indicating whether } \\
\text { to select the } i \text { th transportation cost } \\
\text { level by the distributor's } j \text { th warehouse } \\
(i=1,2, \cdots, I, j=1,2, \cdots, J)\end{array}$ \\
\hline
\end{tabular}
from each of the warehouses to each market, and the

Table 2. List of decision variables. level of Type 1 transportation cost for each warehouse. In the following, two bi-level programming models are proposed based on two power scenarios.

\subsection{Manufacturer-Stackelberg model}

In this model, the manufacturer is the leader while the distributor acts as follower. Considering the profit maximization to be the objective function of both upper-level (manufacturer) and lower-level (distributer) optimization problems, the bi-level programming model will be as follows:

$$
\begin{aligned}
\max _{w, A, T, \theta} \pi_{M}= & (w-f) \cdot D_{0}-1 / T \cdot u_{M} \\
& -D_{0} T / 2 \cdot \rho_{M} \cdot f-A-\theta \cdot \sum_{k=1}^{K} a_{k},
\end{aligned}
$$

S.t.

$$
\begin{aligned}
& \left(r, a_{k}, x_{j k}, y_{i}^{j}\right) \in \arg \max \pi_{D}=r \cdot w \cdot D_{0} \\
& -1 / T \cdot \sum_{j=1}^{J} u_{D}^{j}-w \cdot T / 2 \sum_{j=1}^{J} \sum_{k=1}^{K} x_{j k} \cdot \rho_{D}^{j} \\
& -(1-\theta) \cdot \sum_{k=1}^{K} a_{k}-1 / T \cdot \sum_{j=1}^{J} \sum_{i=1}^{I} s_{i} \cdot y_{i}^{j} \\
& -\sum_{j=1}^{J} \sum_{k=1}^{K} c_{j} k \cdot x_{j} k \\
& D_{0}=\sum_{k=1}^{K} D_{k} \leq \min \left(\sum_{j=1}^{J} b_{j}, G\right) \\
& \sum_{k=1}^{K} x_{j} k \leq b_{j} ; \quad j=1,2, \cdots, J, \\
& \sum_{j=1}^{J} x_{j} k=D_{k} ; \quad k=1,2, \cdots, K, \\
& q_{i-1} \cdot y_{i}^{j} \leq \sum_{k=1}^{K} x_{j k} \cdot T<q_{i} \cdot y_{i}^{j}+M .\left(1-y_{i}^{j}\right) \\
& i=1,2, \cdots, I, \quad j=1,2, \cdots, J, \quad q_{0}=0, \\
& \sum_{i=1}^{I} y_{i}^{j}=1 ; \quad j=1,2, \cdots, J \\
& r, a_{k}, x_{j} k \geq 0 ; \quad j=1,2, \cdots, J, \quad k=1,2, \cdots, K, \\
& y_{i}^{j}=0 \text { or } 1 ; \quad i=1,2, \cdots, I, \quad j=1,2, \cdots, J, \\
& A \geq 0, \quad 0 \leq \theta \leq 1, \quad \varepsilon \leq T \leq 1, \quad w \geq f .
\end{aligned}
$$


The manufacturer's profit is obtained by subtracting setup cost, inventory holding cost, and costs of global advertising as well as participation in local advertising activities from his revenues. Further, the distributor's profit will be equal to their revenues minus the sum of ordering cost, inventory holding cost, local advertising cost, and transportation costs of Types 1 and 2 .

From the structure of the model, it is obvious that level 2 (distributor) optimization problem is seen to be one of the constraints in the level 1 (manufacturer) optimization problem.

\subsection{Distributor-Stackelberg model}

Transmitting the power from the manufacturer to the distributor, we arrive at the distributor-Stackelberg model with switched roles where the distributor leads the chain with the manufacturer as the follower:

$$
\begin{aligned}
\max _{r, a_{k}, x_{j k}, y_{i}^{j}} \pi_{D} & =r \cdot w \cdot D_{0}-1 / T \cdot \sum_{j=1}^{J} u_{D}^{j} \\
& -w \cdot T / 2 \sum_{j=1}^{J} \sum_{k=1}^{K} x_{j k} \cdot \rho_{D}^{j}-(1-\theta) \cdot \sum_{k=1}^{K} a_{k} \\
& -1 / T \cdot \sum_{j=1}^{J} \sum_{i=1}^{I} s_{i} \cdot y_{i}^{j}-\sum_{j=1}^{J} \sum_{k=1}^{K} c_{j k} \cdot x_{j k},
\end{aligned}
$$

S.t.

$$
\begin{aligned}
& (w, A, T, \theta) \in \arg \max \pi_{M}=(w-f) \cdot D_{0}-1 / T \cdot u_{M} \\
& \quad-D_{0} T / 2 . \rho_{M} \cdot f-A-\theta \cdot \sum_{k=1}^{K} a_{k}, \\
& D_{0}=\sum_{k=1}^{K} D_{k} \leq \min \left(\sum_{j=1}^{J} b_{j}, G\right), \\
& \sum_{k=1}^{K} x_{j k} \leq b_{j} ; \\
& j=1,2, \cdots, J, \sum_{j=1}^{J} x_{j k}=D_{k} ; \quad k=1,2, \cdots, K, \\
& q_{i-1} . y_{i}^{j} \leq \sum_{k=1}^{K} x_{j k} \cdot T<q_{i} \cdot y_{i}^{j}+M .\left(1-y_{i}^{j}\right) ; \\
& i=1,2, \cdots, I, \quad j=1,2, \cdots, J, \quad q_{0}=0, \\
& \sum_{i=1}^{I} y_{i}^{j}=1 ; \quad j=1,2, \cdots, J, \quad w \geq f, \\
& A \geq 0, \quad 0 \leq \theta \leq 1, \quad \varepsilon \leq T \leq 1,
\end{aligned}
$$

$$
\begin{aligned}
& r, a_{k}, x_{j k} \geq 0 ; \quad j=1,2, \cdots, J, \quad k=1,2, \cdots, K, \\
& y_{i}^{j}=0 \text { or } 1 ; \quad i=1,2, \cdots, I, \quad j=1,2, \cdots, J .
\end{aligned}
$$

The optimal solution to a bi-level programming problem is referred to as Stackelberg Equilibrium. Considering the presence of non-linear functions as objective and constraints in both the proposed models and the complexity of solving a bi-level programming problem that, even in its simplest form (linear objective function and constraint), has been proved to be NP-hard, two genetic algorithms with hierarchical structure are developed to provide near optimal solutions for the bi-level programming models in the next section. It is worth noting that although algorithms based on a local search structure [31-35] can be considered to deal with the research problem, algorithms accompanied by a population-based structure present better performance. The reason lies in the fact that a basic local search algorithm providing a single solution in each iteration might not be able to generate good quality solutions for such a complex problem in a reasonable time.

\section{Genetic algorithms}

Genetic Algorithm (GA) is one the most robust natural evolution-based stochastic search techniques designed by the principles of genetic processes in biologic organisms. Among the features of this meta-heuristic algorithm is that it does not require any particular condition, such as differentiability or convexity of the objective function, or problem constraints to be applicable [36].

Emphasizing such a distinctive feature, the present research develops two hierarchical GAs for solving bi-level programming model. Each hierarchical GA is composed of two GAs in two different levels, one for solving the upper-level problem and the other for solving the lower-level one; these are related to each other. In each iteration of the upper-level GA, a full run of the lower-level GA is undertaken and the obtained solution is fed into the upper-level algorithm.

\subsection{Representation}

Figure 4 demonstrates how the decision variables of manufacturer and distributer are represented as chromosomes in the proposed GAs. The distributor's problem involves 4 sets of decision variables out of which $x_{j k}$ and $y_{i}^{j}$ sets can be computed based on the first pair of sets, i.e. $r$ and $a_{k}$.

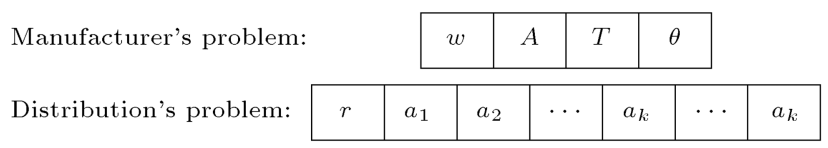

Figure 4. Chromosome representation. 


\subsection{Initialization}

Our approach to deal with the existing constraints is to analyze and identify the relations among the decision variables so as to set allowed ranges for each decision variable in order to prevent infeasible solutions from being generated. Eqs. (11) and (12) are considered as the main constraints in the proposed optimization models:

$$
\begin{aligned}
& w \cdot(1+r) \leq \min _{k=1, \cdots, K}\left\{\frac{1}{\alpha_{k}}\right\} \\
& \sum_{k=1}^{K} z_{k}\left(1-\alpha_{k} \cdot p\right)^{1 / v_{k}}\left[n_{k}^{1} \sqrt{A}+n_{k}^{2} \sqrt{a_{k}}\right] \\
& \leq \min \left\{\sum_{j=1}^{J} b_{j}, G\right\} .
\end{aligned}
$$

\subsubsection{Manufacturer-Stackelberg model}

Assuming the minimum expected retail profit ratio of MAMD (Minimum Attractive Margin of distributer) for the distributor, the allowed ranges for variables $w$ and $A$ are calculated based on Eqs. (11) and (12) as follows:

$$
\begin{aligned}
& f \leq w \leq \frac{\min _{k=1, \cdots, K}\left\{\frac{1}{\alpha_{k}}\right\}}{1+\operatorname{MAMD}}, \\
& 0 \leq A \leq\left(\frac{\min \left\{\sum_{j=1}^{J} b_{j}, G\right\}}{\sum_{k=1}^{K} z_{k}\left(1-\alpha_{k} \cdot p_{\max }\right)^{1 / v_{k}} \cdot n_{k}^{1}}\right)^{2} ; \\
& p_{\max }=\min _{k=1, \cdots, K}\left\{\frac{1}{\alpha_{k}}\right\} .
\end{aligned}
$$

Furthermore, similar to the presented models, we have $\varepsilon \leq T \leq 1$ and $0 \leq \theta \leq 1$. Once the values of $w$ and $A$ are determined in each iteration of the level 1 algorithm, an upper limit for $r$ can be calculated from the equation below:

$$
r_{U}=\frac{\min _{k=1, \cdots, K}\left\{\frac{1}{\alpha_{k}}\right\}}{w}-1 \text {. }
$$

In order to compute the lower limit for $r$, we define the function $f(r)$ as follows:

$$
\begin{aligned}
f(r)= & \min \left\{\sum_{j=1}^{J} b_{j}, G\right\} \\
& -\sum_{k=1}^{K} z_{k}\left(1-\alpha_{k} \cdot w(1+r)\right)^{1 / v_{k}} n_{k}^{1} \cdot \sqrt{A} .
\end{aligned}
$$

Considering the upper limit defined in the previous step, one may prove that the derivative of $f(r)$ is always a positive value except for $r=r_{U}$ :

$f^{\prime}(r)=\sum_{k=1}^{K} \frac{\alpha_{k} \cdot w}{v_{k}} \cdot z_{k} \cdot n_{k}^{1} \sqrt{A}\left(1-\alpha_{k} \cdot w(1+r)\right)^{1 / v_{k}-1} \geq 0$

Knowing that $f(r)$ is a strictly increasing function, the Newton-Raphson method can be used to determine the lower limit for $r$.

Accordingly, taking $r_{0}=r_{U}$ and running the algorithm until the termination criteria are reached, an approximate root of $f(r)$ can be calculated. Denoting the root by $\tilde{r}$, the lower limit for the decision variable $r$ is determined as follows:

$$
r_{L}=\max \{\tilde{r}, \mathrm{MAMD}\} .
$$

In contrast to the manufacturer's variables (level 1 ), the distributor variables (level 2) including $r$ and $a_{k}$ are not independent in terms of value. That is, the value taken by each of them affects the upper and lower limits for the other variable. Therefore, once freely set, they may result in violation of Constraint (12).

Thus, the value of decision variable $r$ is randomly generated within the allowed range of $r \in\left[r_{L}, r_{U}\right]$. In the next step, one of the markets is randomly selected for which the upper limit $a_{k}$ is calculated via Constraint (12). Then, a random value of $a_{k}$ is generated within the calculated range and the process continues until the values of all $a_{k}, k=1, \cdots, K$, are assigned.

\subsubsection{Distributor-Stackelberg model}

Based on Eq. (11) and assuming the minimum expected wholesale profit ratio of MAMM (Minimum Attractive Margin of anufacturer) for the manufacturer, we have:

$$
0 \leq r \leq \frac{\min _{k=1, \cdots, K}\left\{\frac{1}{\alpha_{k}}\right\}}{f .(1+\text { MAMM })}-1
$$

Knowing the value of $r$, the values of $a_{k}$ variables can be obtained similar to the algorithm presented in the previous section. In the above-mentioned algorithm, the value of $p$ is set to its lower limit in order to guarantee the satisfaction of Constraint (12) in the lower-level GA:

$$
p=p_{L}=w_{L} \cdot(1+r), \quad w_{L}=f \cdot(1+\mathrm{MAMM}) .
$$

According to the previous discussions, the allowed ranges of decision variables of the manufacturer are determined by Eqs. (20) to (22), as shown in Box I, to ensure that Constraints (11) and (12) are satisfied. 


$$
\begin{aligned}
& f \cdot(1+\mathrm{MAMM}) \leq w \leq \frac{\min _{k=1, \cdots, K}\left\{\frac{1}{\alpha_{k}}\right\}}{1+r}, \\
& 0 \leq A \leq\left(\frac{\min \left\{\sum_{j=1}^{J} b_{j}, G\right\}-\sum_{k=1}^{K} z_{k}\left(1-\alpha_{k} \cdot w \cdot(1+r)\right)^{1 / v_{k}} n_{k}^{2} \cdot \sqrt{a_{k}}}{\sum_{k=1}^{K} z_{k}\left(1-\alpha_{k} \cdot w \cdot(1+r)\right)^{1 / v_{k}} n_{k}^{1}}\right)^{2},
\end{aligned}
$$

$\theta \in[0,1]$ and $T \in[\varepsilon, 1]$.

\subsection{Fitness evaluation}

Since the fitness function has positive aspect and its value is desired to be increased, the objective functions for level 1 and level 2 problems, i.e. the profit gained by the members, are taken as fitness functions for the GAs. In order to evaluate the generated solutions for the level 1 problem, the values of decision variables in the level 2 problem must be determined in advance. For this purpose, the upper-level GA, during the step of fitness evaluation, heads into the lower-level GA and the optimal (near optimal) values of decision variables in level 2 are obtained by using the values of decision variables from level 1 and performing a full run of the lower-level GA.

Knowing that each solution of the distributor problem contains a set of values of $r$ and $a_{k}$, the value of $x_{j k}$ is determined by solving the assignment problem (i.e., the transportation problem described in the previous section).

Being a part of the objective function and constraints of the Stackelberg models, this linear optimization problem is solved by MATLAB linear optimization tools at each round of fitness evaluation in the lowerlevel GA. Once the values of $x_{j k}$ are determined, the optimal values of $y_{i}^{j}$ are calculated using Eqs. (7) and (8).

\subsection{Selection operator}

In the developed GAs for both Stackelberg models, the Roulette Wheel method with selection pressure is used to select parent chromosomes for cross over operation, while random selection approach is followed to select parent chromosome for mutation.

The concept of selection pressure refers to the degree of desirability provided by a better solution (with higher fitness). The higher the value of this parameter, the higher will be the desirability of solutions with high fitness and the lower will be the desirability of the solutions with low fitness values [37].

Since the convergence of a GA is highly dependent on the selection pressure parameter, it is important to set a proper value for this parameter. If it is underestimated, it will take a longer time for the algorithm to converge, i.e. unnecessarily excessive time will be wasted to reach the solution. However, if it is set at a very high value, the algorithm will come to a premature convergence and gets trapped within local optima [37]. Denoting the selection pressure parameter $\beta(\beta \geq 0)$, the probability of the $i$ th solution in the population to be selected can be determined via the following relationship:

$$
\operatorname{Pr}(i)=\frac{\operatorname{Fit}(i)^{\beta}}{\sum_{i=1}^{n P o p} \operatorname{Fit}(i)^{\beta}} ; \quad i=1, \cdots, n P o p,
$$

where $n P o p$ is the population size and $\operatorname{Fit}(i)$ is the fitness value for the $i$ th solution. It is obvious that:

$$
\operatorname{Pr}(i)= \begin{cases}\frac{1}{n P o p} & \text { if } \beta=0 \\ 1 & \text { if } \beta=\infty \text { and the } i \text { th solution } \\ 0 & \text { is the best solution } \\ & \text { if } \beta=\infty \text { and the } i \text { th solution } \\ & \text { is not the best solution }\end{cases}
$$

\subsection{Crossover operator}

In each iteration of the GAs, $N_{c}$ solutions, out of the previous population, are selected via Roulette Wheel method for crossover operation. Denoting crossover probability by $P_{c}$, which is among parameters of a GA, the value of $N_{c}$ can be calculated via the following equation:

$$
N_{c}=2 \times\left\lceil\frac{P_{c} \cdot n P o p}{2}\right\rceil .
$$

Arithmetic crossover operator is used to generate offspring, which is a linear combination of the parent chromosomes. Figure 5 depicts parent chromosomes $X$ and $Y$, each composed of $n$ components (genes). 


\begin{tabular}{|c|c|c|c|c|}
\hline$x_{1}$ & $x_{2}$ & $x_{3}$ & $\cdots$ & $x_{n}$ \\
\hline \hline$y_{1}$ & $y_{2}$ & $y_{3}$ & $\cdots$ & $y_{n}$ \\
\hline
\end{tabular}

Figure 5. Two sample chromosomes.

Offspring chromosomes are generated via the following relationships [38]:

$$
\begin{aligned}
& x_{i}^{\text {new }}=\lambda \cdot x_{i}+(1-\lambda) \cdot y_{i} ; \quad i=1, \cdots, n, \\
& y_{i}^{\text {new }}=(1-\lambda) \cdot x_{i}+\lambda \cdot y_{i} ; \quad i=1, \cdots, n,
\end{aligned}
$$

where $\lambda$ is a positive constant randomly selected in each step of operator implementation. It is clear that if $0 \leq$ $\lambda \leq 1$, each gene in an offspring chromosome would have a value within the range of values of corresponding genes in its parent's chromosomes.

In this research, in order to diversify reproduced solutions, the value of $\lambda$ is randomly generated in the range of $[-\gamma, 1+\gamma](\gamma \geq 0)$. Selecting a higher value for $\gamma$ allows for producing higher or lower values than the values for the parent chromosomes, so as to enhance diversification across the reproduced solutions. The above mentioned crossover operator is used in lower and upper level GAs within both Stackelberg models.

\subsection{Mutation operator}

Within each iteration of the proposed GAs, $N_{m}$ solutions are selected via random selection approach from the previous population to apply mutation. Denoting mutation probability by $P_{m}$ as one of the GA parameters, $N_{m}$ can be determined via the following equation:

$$
N_{m}=\left\lceil P_{m} \cdot n \operatorname{Pop}\right\rceil .
$$

The mutation operator applies to $n_{m}=n . \psi_{m}$ out of $n$ components (genes) in the selected parent chromosome. In this relation, $\psi_{m}$ denotes mutation effectiveness rate $\left(0 \leq \psi_{m} \leq 1\right)$, which is considered to be a parameter of $\mathrm{GA}$.

The value of $i$ th component within the selected parent chromosome $\left(x_{i}\right)$ changes during the mutation process and a new random value is assigned to it. The new value of the $i$ th component within the selected parent chromosome $\left(x_{i}^{\text {new }}\right)$ is obtained from a normal probability distribution with $x_{i}$ and $\sigma^{2}$ being its mean and variance, respectively $\left(x_{i}^{\text {new }} \sim N\left(x_{i}, \sigma^{2}\right)\right)$.

Standard deviation $(\sigma)$, as mutation step length, is determined as being proportional to the search space width:

$$
\sigma=\mu \times\left(\bar{x}_{i}-\underline{x}_{i}\right),
$$

where $\mu$ is a constant positive coefficient ranging from 0 to $1(0<\mu<1)$, while $\underline{x}_{i}$ and $\bar{x}_{i}$ are the lower and upper limits of the $i$ th component within the parent chromosome, respectively. The longer the mutation step length $(\sigma)$, the higher diversification and lower intensification will be realized, and vice versa. We considered $\mu=0.1$ in the proposed GAs for solving Stackelberg models.

\subsection{Correction of infeasible solutions}

Except for $a_{k}$, all decision variables are limited within the previously calculated ranges. In order to rectify the values of $a_{k}$ variables, one of the markets is randomly selected and its $a_{k}$ is multiplied by the fixed value of 0.99. This process continues until Eq. (12) is satisfied. For calculating the value of the mentioned equation in distributer-Stackelberg model, it is assumed that $A=0$ and $W=W_{L}=f .(1+\mathrm{MAMM})$.

\subsection{Reproduction and termination criterion}

For all developed GAs, new generations are formed based on the elitism approach (merging old solutions with new ones and selecting $n$ Pop better solutions).

Furthermore, the termination criterion for all algorithms is set to be reaching a given number of iterations $\left(\max _{I t}\right)$. This limit is considered as one of the parameters of the GAs as well.

The steps of the developed hierarchical GAs for manufacturer-Stackelberg and distributer-Stackelberg models are demonstrated in Figures 6 and 7, respectively.

In the following, we use design of experiment approach to set the parameters of the four developed GAs. Table 3 reports the levels considered for the parameters.

Table 4 contains the results of implementing a full factorial design including $7^{3}$ test combinations (treatments), each being comprised of 2 runs, along with selected values for parameters. As the lowerlevel GAs need the values of decision variables of the upper-level GAs, for each test, the mentioned values are randomly generated in such a way that reasonable relations among the variables are respected.

\section{Computational experiments}

First, we present a numerical example. Then, 15 problem samples are defined and the obtained results are compared.

In order to analyze the results, three test problems are designed in terms of the number of warehouses $(J)$ and the number of markets $(K)$ and for each one, five

Table 3. Levels of parameters.

\begin{tabular}{cccccccc}
\hline Parameter: & $\boldsymbol{n P o p}$ & $\boldsymbol{m a x}_{\boldsymbol{I t}}$ & $\boldsymbol{\beta}$ & $\boldsymbol{p}_{\boldsymbol{c}}$ & $\boldsymbol{\gamma}$ & $\boldsymbol{p}_{\boldsymbol{m}}$ & $\boldsymbol{\psi}_{\boldsymbol{m}}$ \\
\hline Level 1: & 30 & 50 & 1 & 0.5 & 0.5 & 0.45 & 0.4 \\
Level 2: & 40 & 80 & 1.5 & 0.6 & 1 & 0.55 & 0.5 \\
Level 3: & 50 & 100 & 2 & 0.7 & 1.5 & 0.6 & 0.6 \\
\hline
\end{tabular}



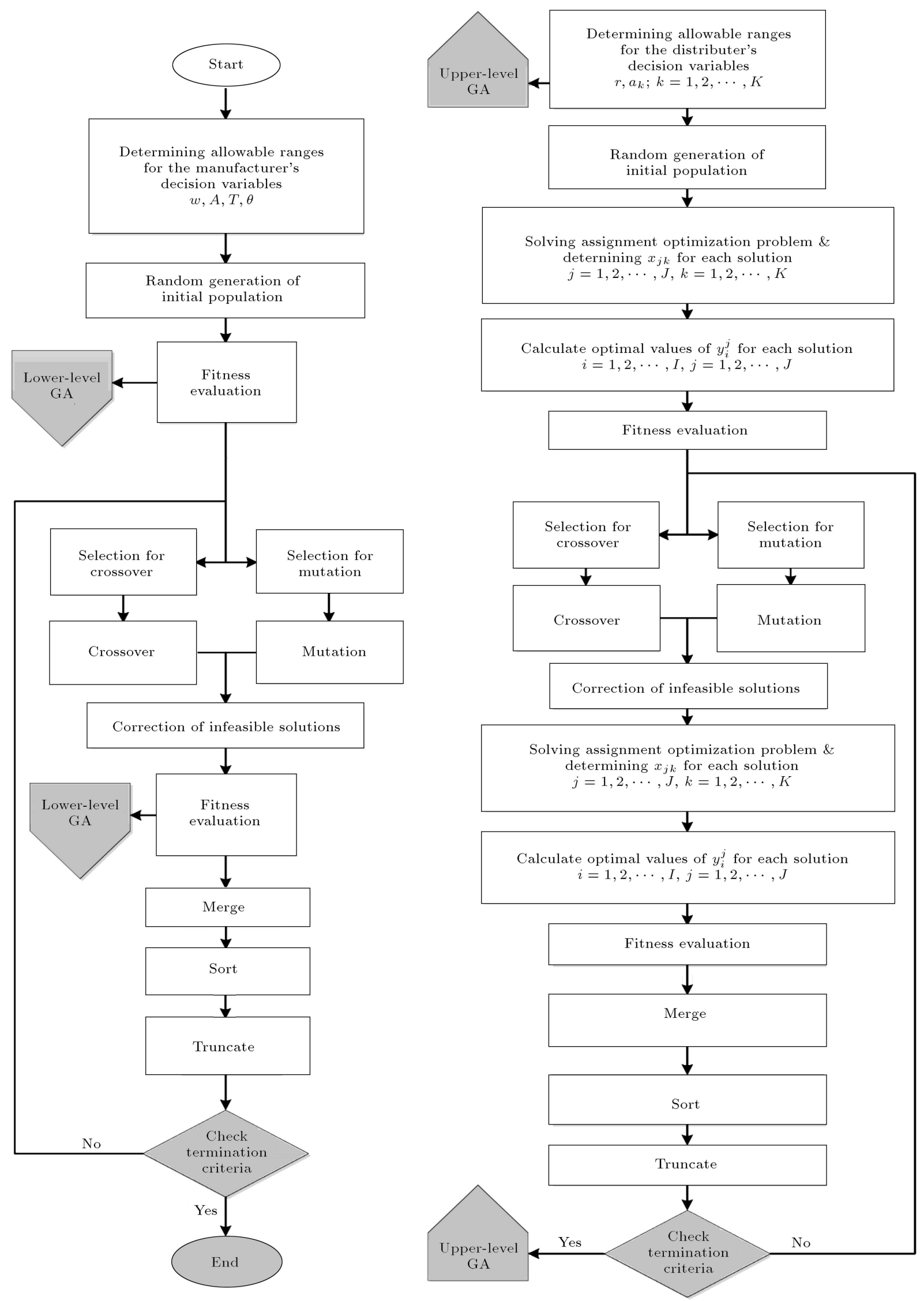

Figure 6. Hierarchical GA for manufacturer-Stackelberg model. 


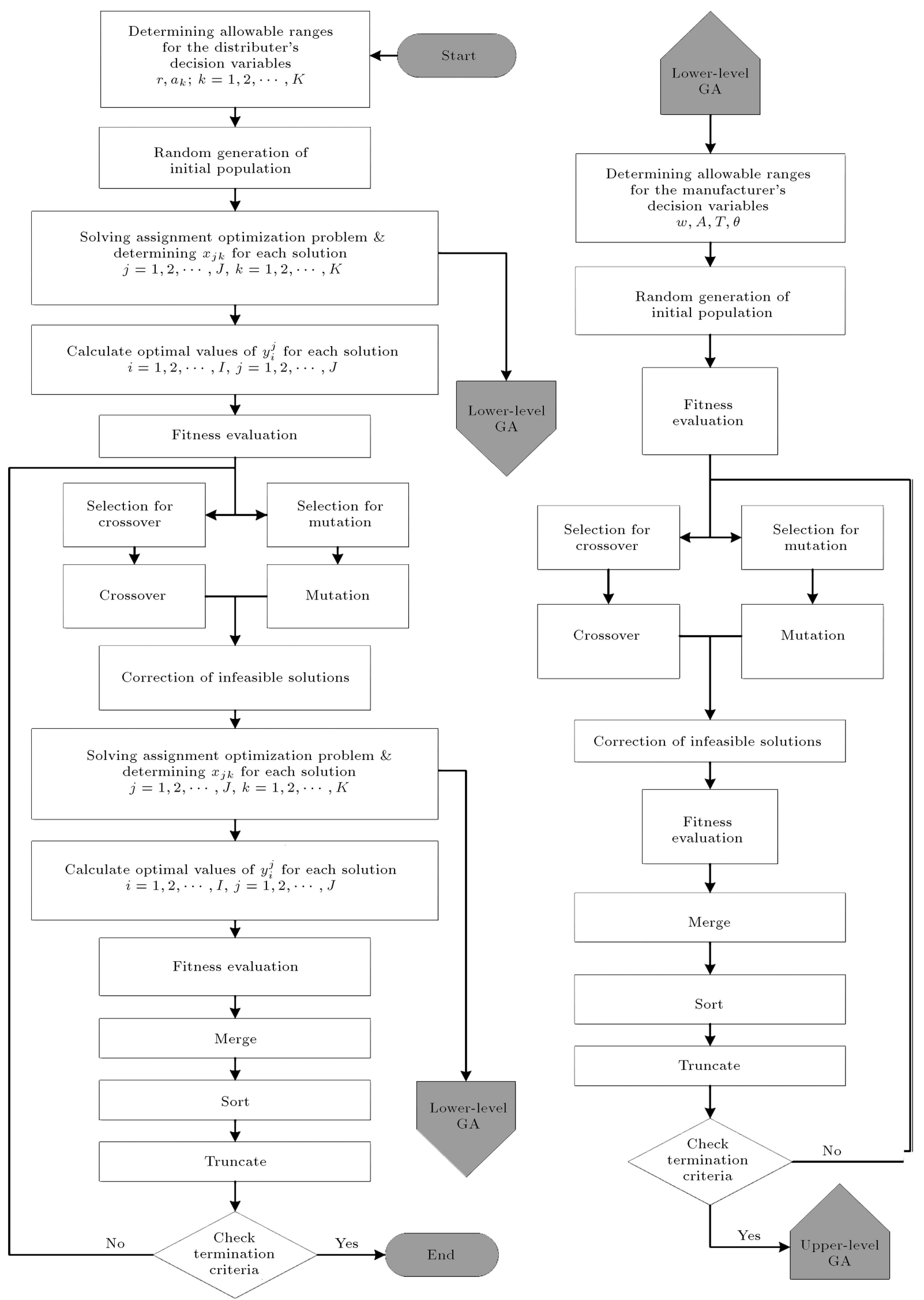

Figure 7. Hierarchical GA for distributer-Stackelberg model. 
Table 4. Results of GAs parameters settings.

\begin{tabular}{cccccc}
\hline \multirow{2}{*}{ Parameter } & \multicolumn{2}{c}{$\begin{array}{c}\text { Manufacturer-Stackelberg } \\
\text { model }\end{array}$} & & \multicolumn{2}{c}{$\begin{array}{c}\text { Distributor-Stackelberg } \\
\text { model }\end{array}$} \\
\cline { 2 - 3 } \cline { 5 - 6 } \cline { 5 - 6 } & Level 1 & Level 2 & & Level 1 & Level 2 \\
\hline $\max _{I t}$ & 40 & 50 & & 30 & 30 \\
$\beta$ & 1.5 & 1 & & 80 & 80 \\
$P_{c}$ & 0.7 & 0.7 & & 1.5 & 1.5 \\
$\gamma$ & 1 & 1.5 & & 0.6 & 0.7 \\
$P_{m}$ & 0.55 & 0.6 & & 0.55 & 0.5 \\
$\psi_{m}$ & 0.6 & 0.6 & & 0.6 & 0.5 \\
\hline
\end{tabular}

Table 5. Specified ranges of parameters for the problem samples.

\begin{tabular}{|c|c|c|c|c|c|}
\hline \multicolumn{2}{|c|}{ Manufacturer } & \multicolumn{2}{|c|}{ Distributor } & \multicolumn{2}{|c|}{ Markets } \\
\hline Parameter & Value & Parameter & Value & Parameter & Value \\
\hline$f$ & $U(50,150) \times 10^{3}$ & $b_{j}$ & $U(1,4) \times 10^{5}$ & $z_{k}$ & $U(10000,50000)$ \\
\hline$\rho_{M}$ & 0.02 & $\rho_{D}^{j}$ & 0.02 & $\alpha_{k}$ & $U(0.002,0.005)$ \\
\hline$\mu_{M}$ & $U(20,50) \times 10^{5}$ & $\mu_{D}^{j}$ & $U(300,700) \times 10^{3}$ & $v_{k}$ & $U(0.5,1.5)$ \\
\hline$G$ & $U(300,500) \times 10^{3}$ & $c_{j k}$ & $U(0,5) \times 10^{3}$ & $n_{k}^{1}$ & $U(0,1.5)$ \\
\hline \multirow[t]{3}{*}{ MAMM } & $5 \%$ & MAMD & $5 \%$ & $n_{k}^{2}$ & $U(0,1.5)$ \\
\hline & & $q_{i}$ & {$[0,15000,25000]$} & & \\
\hline & & $s_{i}$ & {$[1,1.8,2.4] \times 10^{3}$} & & \\
\hline
\end{tabular}

problem samples with random parameters are considered. Table 5 reports the specified ranges within which to generate parameter values in a random fashion. The ranges are determined based on the comments received from experts in the field of automotive spare parts production and distribution in Iran. As the type of considered spare part, in terms of its value, weight, consumption rate, and application in the car, affects the value of problem parameters, the liner and piston kit of the car engine is considered in this research.

As a numerical example, the first problem sample from test problem 1 with its data being indicated in Table 6 is solved by using developed hierarchical algorithms; the convergence diagrams corresponding

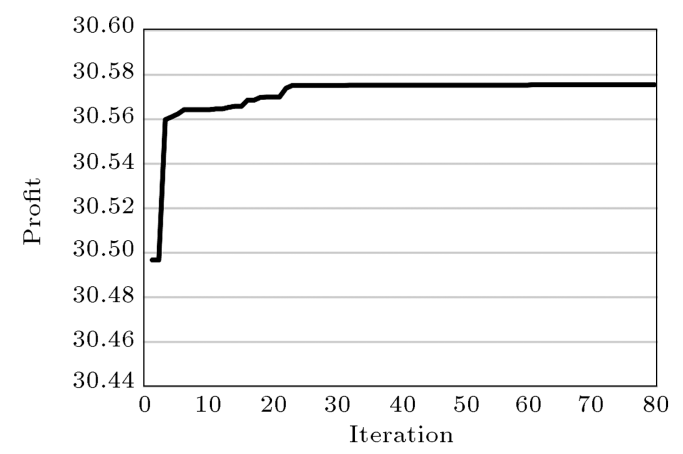

(a) to each of four genetic algorithms are presented in Figures 8 and 9 .

The values of decision variables of both the manufacturer and the distributor are presented in Table 7. Regarding the pricing policy, although the same selling price of 222,000 is offered to the markets in both Stackelberg models, the wholesale price for the manufacturer and the retail profit ratio for the distributor are higher when they are the chain leader. The other point is that in the manufacturer-Stackelberg model, the ratio of retail profit for the distributor is $5 \%$ which is equal to its minimum allowable value (MAMD).

From the advertising perspective, the manufac-

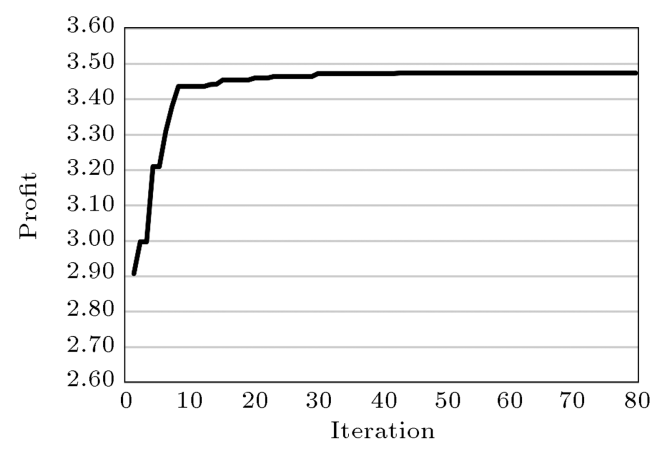

(b)

Figure 8. Convergence of the upper-level (a) and lower-level (b) GAs in the manufacturer-Stackelberg model. 


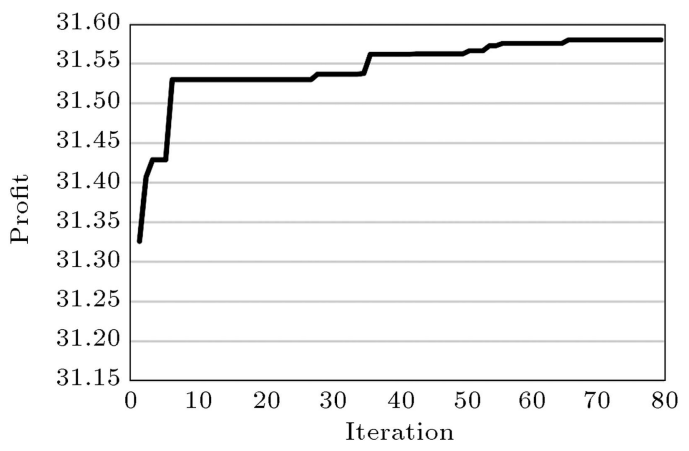

(a)

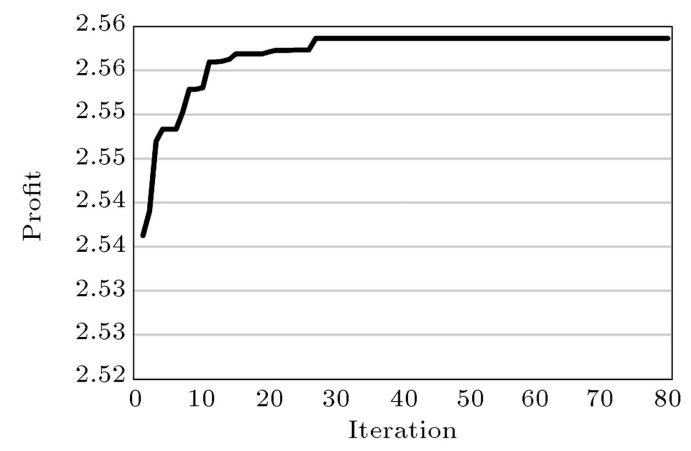

(b)

Figure 9. Convergence of the upper-level (a) and lower-level (b) GAs in the distributer-Stackelberg model.

Table 6. Parameter values for the problem sample 1 in the first test problem.

\begin{tabular}{|c|c|c|c|c|c|}
\hline \multicolumn{2}{|c|}{ Manufacturer } & \multicolumn{2}{|c|}{ Distributor } & \multicolumn{2}{|c|}{ Markets } \\
\hline Parameter & Value & Parameter & Value & Parameter & Value \\
\hline$f$ & 135,000 & {$\left[b_{1}, b_{2}\right]$} & {$[300,200] \times 10^{3}$} & {$\left[z_{1}, z_{2}, z_{3}\right]$} & {$[80,40,65] \times 10^{3}$} \\
\hline$\rho_{M}$ & 0.02 & {$\left[\rho_{D}^{1}, \rho_{D}^{2}\right]$} & 0.02 & {$\left[\alpha_{1}, \alpha_{2}, \alpha_{3}\right]$} & {$[3.5,4.5,4] \times 10^{-3}$} \\
\hline$\mu_{M}$ & $3,000,000$ & {$\left[\mu_{D}^{1}, \mu_{D}^{2}\right]$} & {$[350,400] \times 10^{3}$} & {$\left[v_{1}, v_{2}, v_{3}\right]$} & {$[1,0.8,1.3]$} \\
\hline$G$ & 400,000 & {$\left[c_{11}, c_{21}\right]$} & {$[2000,2000]$} & {$\left[n_{1}^{1}, n_{2}^{1}, n_{3}^{1}\right]$} & {$[0.4,0.5,0.45]$} \\
\hline MAMM & $5 \%$ & {$\left[c_{12}, c_{22}\right]$} & {$[1000,4000]$} & {$\left[n_{1}^{2}, n_{2}^{2}, n_{3}^{2}\right]$} & {$[0.3,0.2,0.1]$} \\
\hline & & {$\left[c_{13}, c_{23}\right]$} & {$[3000,1000]$} & & \\
\hline & & MAMD & $5 \%$ & & \\
\hline & & {$\left[q_{1}, q_{2}, q_{3}\right]$} & {$[0,15000,25000]$} & & \\
\hline & & {$\left[s_{1}, s_{2}, s_{3}\right]$} & {$[1000,1800,2400]$} & & \\
\hline
\end{tabular}

Table 7. Solution results for the problem sample 1 in the first test problem.

\begin{tabular}{|c|c|c|c|}
\hline \multirow[b]{2}{*}{ Level } & \multirow[b]{2}{*}{ Decision variable } & \multicolumn{2}{|c|}{ The value of decision variable } \\
\hline & & $\begin{array}{c}\text { Manufacturer-Stackelberg } \\
\text { model }\end{array}$ & $\begin{array}{c}\text { Distributor-Stackelberg } \\
\text { model }\end{array}$ \\
\hline \multirow{5}{*}{ Manufacturer } & $w$ & 211.640 & 141.660 \\
\hline & $A$ & 3.644 & zero \\
\hline & $T$ & 0.078 & 0.057 \\
\hline & $\theta$ & zero & $71.2 \%$ \\
\hline & $\pi_{M}$ & $30,575,487$ & $2,558,645$ \\
\hline \multirow{8}{*}{ Distributor } & $r$ & $5 \%$ & $56.71 \%$ \\
\hline & $a_{1}, a_{2}, a_{3}$ & $1154,0,26401$ & $1120,14836,33775$ \\
\hline & $x_{11}, x_{21}$ & $194,789,0$ & $179,695,0$ \\
\hline & $x_{12}, x_{22}$ & 0,0 & 173,0 \\
\hline & $x_{13}, x_{23}$ & 5210,200000 & 22180,200000 \\
\hline & $y_{1}^{1}, y_{2}^{1}, y_{3}^{1}$ & $0,1,0$ & $1,0,0$ \\
\hline & $y_{1}^{2}, y_{2}^{2}, y_{3}^{2}$ & $0,1,0$ & $1,0,0$ \\
\hline & $\pi_{D}$ & $3,474,010$ & $31,579,805$ \\
\hline \multirow{3}{*}{ System } & $p$ & 222.212 & 222 \\
\hline & $D_{1}, D_{2}, D_{3}$ & $194789,0,205210$ & $179695,173,222180$ \\
\hline & $\pi_{M+D}$ & $34,049,497$ & $34,138,450$ \\
\hline
\end{tabular}


turer's rate of participation in local advertising cost $(\theta)$ is zero and $71.2 \%$ in the manufacturer- and distributerStackelberg models, respectively. This means that when the manufacturer is the leader, they do not exhibit any interest in participating in local advertising cost as they attempt to maximize their profit via increasing the wholesale price. Regarding the inventory management, the production (replenishment) interval is seen to be longer in the manufacturer-Stackelberg model. Since, based on the model assumptions, the manufacturer controls this variable; they tend to lengthen the interval, to increase the production lot size and to decrease the frequency of replenishment. Therefore, the value of this variable is observed to be higher in the manufacturer-Stackelberg model.

From the demand allocation perspective, in each of Stackelberg models, the optimized allocation of markets' demands to the distributor's warehouses is determined along with Type 1 transportation cost levels.

According to the results of the numerical example, the profits of the entire system in both Stackelberg models are approximately equal. However, members will gain considerably higher share of the profit when they are the chain leader.

We examine the above findings in other 14 problem samples. For each sample, the manufacturerStackelberg and the distributor-Stackelberg models are solved using the developed hierarchical GAs, and the members' profits as well as the system profits are compared; the results for all 15 problem samples are summarized in Table 8.
Interestingly, the system profits for manufacturerStackelberg and distributer-Stackelberg models are almost equal in all problem samples. Stochastic nature of GA, which provides near optimal solutions, can justify the small and ignorable difference between the profits. In addition, the member, who is in leader position, gains more share from the system profit. The diagrams depicted in Figures 10-12 demonstrate the members' profits in test problems 1 to 3 , respectively.

In order to validate the results of the proposed GAs, we adopt an exhaustive grid search within the domains of the decision variables to find near optimal solutions for small-size problem instances (test problem 1 with $J=2$ and $K=3$ ).

Exhaustive grid search method creates a grid by partitioning the ranges of decision variables into jointed intervals and evaluates the fitness function for all possible combinations. The intervals corresponding to the best combination are more divided into subintervals and the process is repeated until the length of the last subinterval is less than a predefined tolerance. Grid search is computationally expensive and does not guarantee to find global optima; however, it can yield a lower bound for the profit function of the leader.

Thus, for every problem sample of test problem 1, we apply a grid search algorithm for each Stackelberg model and compare the results with the output of the corresponding GA (see Table 9). For optimization of the follower's problem, we use nonlinear solver of MATLAB optimization tool box in each iteration of the grid search. As for the constraints, we use penalty

Table 8. A comparison between the profits gained by the manufacturer and the distributor in two Stackelberg models.

\begin{tabular}{|c|c|c|c|c|c|c|c|c|c|}
\hline \multirow[b]{2}{*}{ Problem } & \multirow[b]{2}{*}{$\boldsymbol{J}$} & \multirow[b]{2}{*}{$\boldsymbol{K}$} & \multirow{2}{*}{ 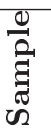 } & \multicolumn{2}{|c|}{ Manufacturer's benefit } & \multicolumn{2}{|c|}{ Distributer's benefit } & \multicolumn{2}{|c|}{ Total benefit } \\
\hline & & & & M-Stackel.* & D-Stackel.** & M-Stackel. & D-Stackel. & M-Stackel. & D-Stackel. \\
\hline \multirow[t]{5}{*}{ Test 1} & 2 & 3 & 1 & $30,575,487$ & $2,558,645$ & $3,474,010$ & $31,579,805$ & $34,049,497$ & $34,138,450$ \\
\hline & & & 2 & $39,708,618$ & $2,421,230$ & $3,716,592$ & $40,798,643$ & $43,425,210$ & $43,219,873$ \\
\hline & & & 3 & $99,033,283$ & 612,219 & $4,783,845$ & $102,877,839$ & $103,817,128$ & $103,490,058$ \\
\hline & & & 4 & $52,602,566$ & $1,302,044$ & $3,604,710$ & $54,927,779$ & $56,207,276$ & $56,229,823$ \\
\hline & & & 5 & $51,185,426$ & $1,432,589$ & $1,929,573$ & $51,676,964$ & $53,114,999$ & $53,109,553$ \\
\hline \multirow[t]{5}{*}{ Test 2} & 3 & 5 & 1 & $30,421,220$ & $1,534,660$ & $2,406,874$ & $31,237,772$ & $32,828,094$ & $32,772,432$ \\
\hline & & & 2 & $37,832,976$ & $1,404,526$ & $2,387,680$ & $39,330,579$ & $40,220,656$ & $40,735,105$ \\
\hline & & & 3 & $12,300,976$ & $1,135,689$ & $1,051,341$ & $12,815,147$ & $13,352,317$ & $13,950,836$ \\
\hline & & & 4 & $16,588,114$ & $1,375,383$ & $2,028,718$ & $17,230,058$ & $18,616,832$ & $18,605,441$ \\
\hline & & & 5 & $29,566,234$ & 797,181 & $1,760,325$ & $30,466,863$ & $31,326,559$ & $31,264,044$ \\
\hline \multirow[t]{5}{*}{ Test 3} & 5 & 10 & 1 & $43,907,755$ & $1,868,032$ & $3,353,023$ & $45,515,170$ & $47,260,778$ & $47,383,202$ \\
\hline & & & 2 & $38,271,013$ & $1,789,120$ & $3,460,492$ & $39,575,125$ & $41,731,505$ & $41,364,245$ \\
\hline & & & 3 & $41,542,421$ & 730,351 & $2,230,068$ & $43,329,936$ & $43,772,489$ & $44,060,287$ \\
\hline & & & 4 & $25,340,773$ & $1,872,709$ & $2,915,538$ & $26,483,869$ & $28,256,311$ & $28,356,578$ \\
\hline & & & 5 & $44,179,433$ & $2,470,293$ & $3,860,275$ & $46,220,896$ & $48,039,708$ & $48,691,189$ \\
\hline
\end{tabular}

${ }^{*}$ M-Stackel.: Manufacturer-Stackelberg model; ${ }^{* *}$ D-Stackel.: Distributor-Stackelberg model 


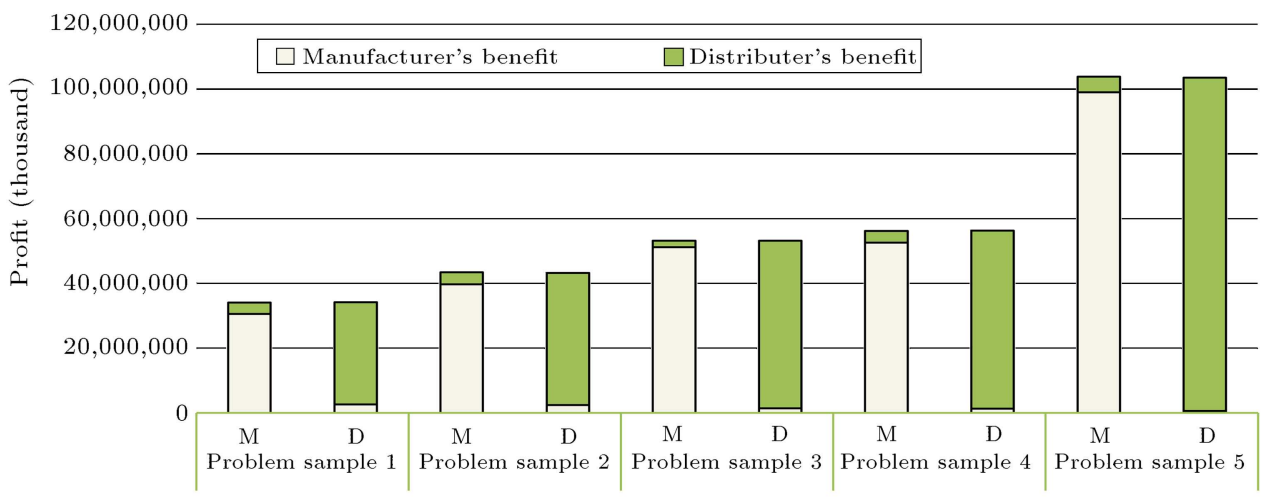

M: Manufacturer-Stackelberg; D: Distributer-Stackelberg

Figure 10. Comparison between the manufacturer and the distributor profits in test problem 1.

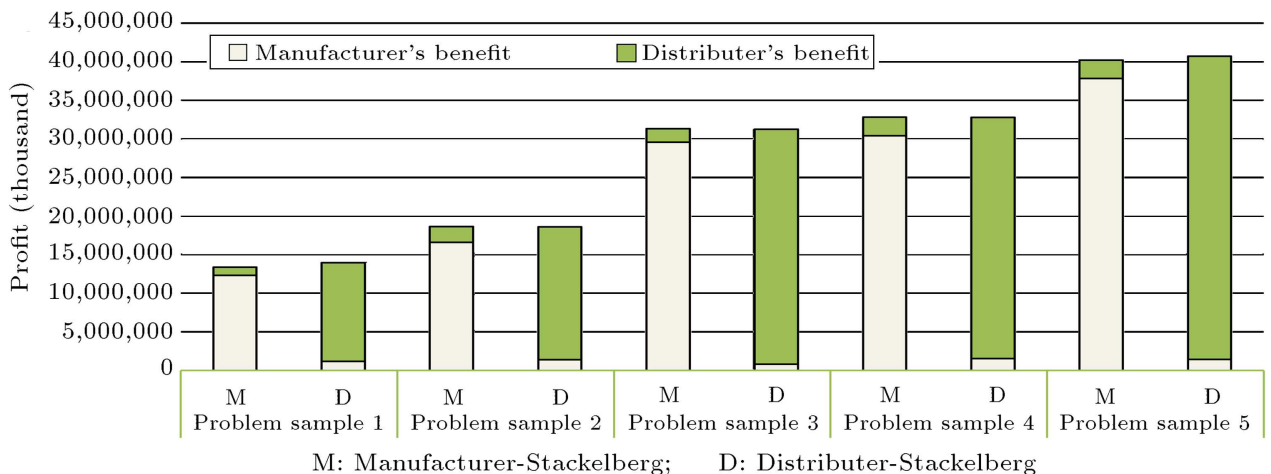

Figure 11. Comparison between the manufacturer and the distributor profits in test problem 2.

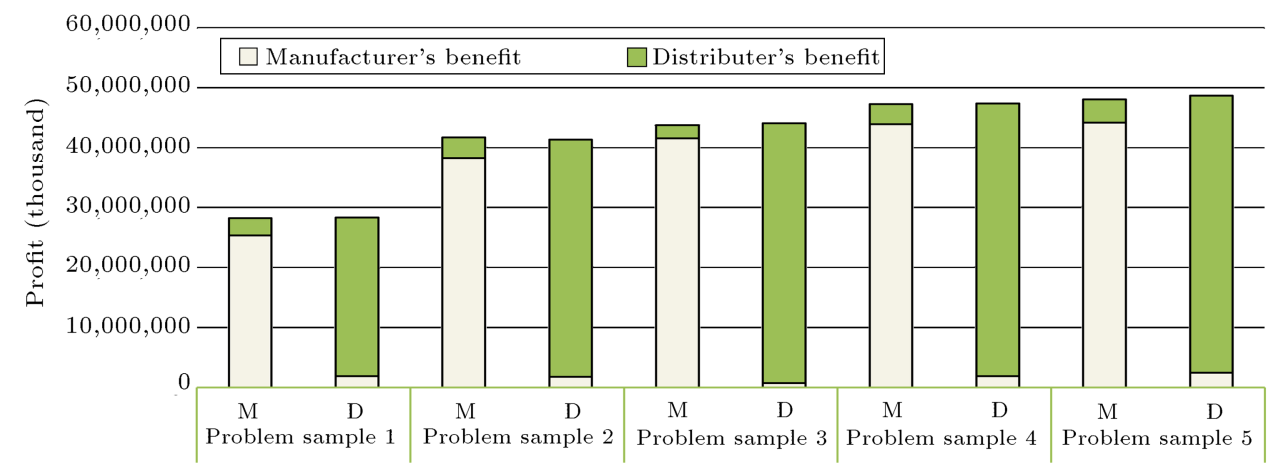

M: Manufacturer-Stackelberg; D: Distributer-Stackelberg

Figure 12. Comparison between the manufacturer and the distributor profits in test problem 3.

Table 9. Results of test problem 1.

\begin{tabular}{|c|c|c|c|c|}
\hline \multirow{2}{*}{ Sample } & \multicolumn{2}{|c|}{$\begin{array}{l}\text { Manufacturer-Stackelberg } \\
\text { model (manufact urer profit) }\end{array}$} & \multicolumn{2}{|c|}{$\begin{array}{l}\text { Distributer Stackelberg } \\
\text { model (distributer profit) }\end{array}$} \\
\hline & Grid search & GA & Grid search & GA \\
\hline 1 & $28,036,371$ & $30,575,487$ & $28,322,194$ & $31,579,805$ \\
\hline 2 & $34,420,481$ & $39,708,618$ & $34,738,581$ & $40,798,643$ \\
\hline 3 & $78,691,503$ & $99,033,283$ & $80,628,406$ & $102,877,839$ \\
\hline 4 & $43,088,694$ & $52,602,566$ & $44,159,610$ & $54,927,779$ \\
\hline 5 & $41,399,725$ & $51,185,426$ & $40,737,283$ & $51,676,964$ \\
\hline
\end{tabular}


function as a famous constraint handling mechanism to prevent generation of infeasible solutions.

Experimental results in Table 9 indicate that the proposed hierarchical GAs exceed the grid search algorithm in finding near optimal solution for both Stackelberg models. It also reveals that the developed grid search algorithms give appropriate lower bounds for the proposed solution procedures.

To summarize the above results, we can conclude that in a decentralized supply chain with the members not cooperating with each other, the member with superior decision-making power will always gain more profit from the total profit available within the entire system while keeping the other member significantly deprived of the system benefits. It should be noted that MAMM and MAMD parameters in the developed models guarantee a minimum profit for both the manufacturer and the distributor, so that decreasing these values or eliminating them from the models may render the follower as being unprofitable.

\section{Conclusions}

This paper studied a decentralized manufacturerdistributer supply chain and modeled the hierarchical relationship between the members in the form of two power scenarios. Solving bi-level programming models, the optimal (near optimal) policies for each member of the chain in terms of pricing, advertising, inventory, and demand allocation were determined.

Two meta-heuristic genetic algorithms with hierarchical structure were developed to tackle bi-level programming models; they were then validated by adopting two exhaustive grid search algorithms based on the collected data from automotive spare parts supply chain.

Furthermore, performing a set of computational experiments, a comparison was made over members' profits as well as those of the entire system in Stackelberg models.

According to the results obtained, the system will gain approximately the same amount of profit under both power scenarios; however, each member's share depends on its position within the hierarchical structure. Putting it in other words, when compared to the follower, the chain leader always captures a major share of the system profit.

Aligned with the previous studies, the above results once more express the necessity of coordination among and integration of the supply chain members. As the coordination level increases across the members and the hierarchical structure of the decision-making process fades, system profit will increase compared to that of a decentralized structure, so that one can implement adequate mechanisms in terms of surplus profit sharing to persuade members to cooperate and get coordinated with each other. Accordingly, developing incentive mechanisms is among the topics to be addressed in future researches.

\section{References}

1. Taleizadeh, A.A., Niaki, S.T.A., and Wee, H.-M. "Joint single vendor-single buyer supply chain problem with stochastic demand and fuzzy lead-time", Knowledge-Based Systems, 48, pp. 1-9 (2013).

2. Giannoccaro, I. and Pontrandolfo, P. "Supply chain coordination by revenue sharing contracts", International Journal of Production Economics, 89(2), pp. 131-139 (2004).

3. Von Stackelberg, H., The Theory of the Market Economy, Oxford University Press (1952).

4. Koh, A. "A metaheuristic framework for bi-level programming problems with multi-disciplinary applications", in Metaheuristics for Bi-Level Optimization, Springer, pp. 153-187 (2013).

5. Hutchins, M.S., Cooperative Advertising: The Way to Make it Pay, Ronald Press (1953).

6. Herrington, J.D. and Dempsey, W.A. "Comparing the current effects and carryover of national-, regional-, and local-sponsor advertising", Journal of Advertising Research, 45(01), pp. 60-72 (2005).

7. Young, R.F. and Greyser, S.A., Managing Cooperative Advertising: A Strategic Approach, Lexington Books (1983).

8. Aust, G. and Buscher, U. "Cooperative advertising models in supply chain management: A review", European Journal of Operational Research, 234(1), pp. 1-14 (2014).

9. Ben-Ayed, O. and Blair, C.E. "Computational difficulties of bilevel linear programming", Operations Research, 38(3), pp. 556-560 (1990).

10. Xie, J. and Ai, S. "A note on "Cooperative advertising, game theory and manufacturer-retailer supply chains", Omega, 34(5), pp. 501-504 (2006).

11. Ming, L., Shuguang, S., and Dan, Y. "A study of the joint advertising channels", Journal of Service Science and Management, 2(04), p. 418 (2009).

12. Tsou, C.-S., Fang, H.-H., Lo, H.-C., and Huang, C.-H. "A study of cooperative advertising in a manufacturerretailer supply chain", International Journal of Information and Management Sciences, 20(1), pp. 15-26 (2009).

13. Ahmadi-Javid, A. and Hoseinpour, P. "On a cooperative advertising model for a supply chain with one manufacturer and one retailer", European Journal of Operational Research, 219(2), pp. 458-466 (2012).

14. Zhang, J., Xie, J., and Chen, B. "Cooperative advertising with bilateral participation", Decision Sciences, 44(1), pp. 193-203 (2013). 
15. Yue, J., Austin, J., Wang, M.-C., and Huang, Z. "Coordination of cooperative advertising in a twolevel supply chain when manufacturer offers discount", European Journal of Operational Research, 168(1), pp. 65-85 (2006).

16. Szmerekovsky, J.G. and Zhang, J. "Pricing and twotier advertising with one manufacturer and one retailer", European Journal of Operational Research, 192(3), pp. 904-917 (2009).

17. Xie, J. and Neyret, A. "Co-op advertising and pricing models in manufacturer-retailer supply chains", Computers \& Industrial Engineering, 56(4), pp. 1375-1385 (2009).

18. Xie, J. and Wei, J.C. "Coordinating advertising and pricing in a manufacturer-retailer channel", European Journal of Operational Research, 197(2), pp. 785-791 (2009).

19. SeyedEsfahani, M.M., Biazaran, M., and Gharakhani, M. "A game theoretic approach to coordinate pricing and vertical co-op advertising in manufacturer-retailer supply chains", European Journal of Operational Research, 211(2), pp. 263-273 (2011).

20. Aust, G. and Buscher, U. "Vertical cooperative advertising and pricing decisions in a manufacturer-retailer supply chain: A game-theoretic approach", European Journal of Operational Research, 223(2), pp. 473-482 (2012).

21. Haifang, C., JinLei, L., and Weilai, H. "A coordination model of cooperative advertising based on revenue sharing contract", in Service Systems and Service Management, 2006 International Conference on, IEEE (2006).

22. Karray, S. "Periodicity of pricing and marketing efforts in a distribution channel", European Journal of Operational Research, 228(3), pp. 635-647 (2013).

23. Kunter, M. "Coordination via cost and revenue sharing in manufacturer-retailer channels", European Journal of Operational Research, 216(2), pp. 477-486 (2012).

24. Yugang, Y., Liang, L., and Huang, G.Q. "Leaderfollower game in vendor-managed inventory system with limited production capacity considering wholesale and retail prices", International Journal of Logistics: Research and Applications, 9(4), pp. 335-350 (2006).

25. Mokhlesian, M. and Zegordi, S.H. "Application of multidivisional bi-level programming to coordinate pricing and inventory decisions in a multiproduct competitive supply chain", The International Journal of Advanced Manufacturing Technology, 71(9-12), pp. 1975-1989 (2014).

26. Sadigh, A.N., Mozafari, M., and Karimi, B. "Manufacturer-retailer supply chain coordination: A bi-level programming approach", Advances in Engineering Software, 45(1), pp. 144-152 (2012).

27. Esmaeili, M., Aryanezhad, M.-B., and Zeephongsekul, P. "A game theory approach in seller-buyer supply chain", European Journal of Operational Research, 195(2), pp. 442-448 (2009).
28. Esmaeili, M. and Zeephongsekul, P. "Seller-buyer models of supply chain management with an asymmetric information structure", International Journal of Production Economics, 123(1), pp. 146-154 (2010).

29. Swami, S. and Shah, J. "Channel coordination in green supply chain management: The case of package size and shelf-space allocation", Technology Operation Management, 2(1), pp. 50-59 (2011).

30. Simon, J.L. and Arndt, J. "The shape of the advertising response function", Journal of Advertising Research, 20(4), pp. 11-28 (1980).

31. Shahvari, O. and Logendran, R. "An enhanced tabu search algorithm to minimize a bi-criteria objective in batching and scheduling problems on unrelatedparallel machines with desired lower bounds on batch sizes", Computers and Operations Research, 77, pp. 154-176 (2017).

32. Shahvari, O. and Logendran, R. "Hybrid flow shop batching and scheduling with a bi-criteria objective", International Journal of Production Economics, 179, pp. 239-258 (2016).

33. Shahvari, O. and Logendran, R. "Bi-criteria batch scheduling in hybrid flow shop", Proceedings of the 2016 Industrial and Systems Engineering Research Conference (ISERC2016), California, USA (2016).

34. Shahvari, O. and Logendran, R. "Bi-criteria batch scheduling on unrelated-parallel machines", Proceedings of the 2015 Industrial and Systems Engineering Research Conference (ISERC2015), Tennessee, USA (2015).

35. Shahvari, O., Salmasi, N., Logendran, R., and Abbasi, B. "An efficient tabu search algorithm for flexible flow shop sequence-dependent group scheduling problems", International Journal of Production Research, 50(15), pp. 4237-4254 (2012).

36. Oduguwa, V. and Roy, R. "Bi-level optimisation using genetic algorithm", in Artificial Intelligence Systems, 2002.(ICAIS 2002). 2002 IEEE International Conference on, IEEE (2002).

37. Sivanandam, S. and Deepa, S., Introduction to Genetic Algorithms, Springer Science \& Business Media (2007).

38. Köksoy, O. and Yalcinoz, T. "Robust design using Pareto type optimization: a genetic algorithm with arithmetic crossover", Computers \& Industrial Engineering, 55(1), pp. 208-218 (2008).

39. Huang, Z., Li, S.X., and Mahajan, V. "An analysis of manufacturer-retailer supply chain coordination in cooperative advertising", Decision Sciences, 33(3), pp. 469-494 (2002).

40. Alirezaei, A. and KhoshAlhan, F. "Coordination of pricing and co-op advertising models in supply chain: A game theoretic approach", International Journal of Industrial Engineering Computations, 5(1), pp. 23-40 (2014).

41. Taleizadeh, A.A. and Charmchi, M. "Optimal advertising and pricing decisions for complementary products", Journal of Industrial Engineering International, 11(1), pp. 111-117 (2015). 


\section{Biographies}

Omid Amirtaheri is currently a $\mathrm{PhD}$ candidate in Production and Operations Management at Shahid Beheshti University. He received his BSc degree in Industrial Engineering from Mazandaran University of Science and Technology in 2007, and his MSc degree from Amirkabir University of Technology in 2010. His research interests are supply chain management, artificial intelligence algorithms, and quantitative decision making techniques.

Mostafa Zandieh received his BSc degree in Industrial Engineering from Amirkabir University of Technology, Tehran, Iran, in 1998, and MSc degree in Industrial Engineering from Sharif University of Technology, Tehran, Iran, in 2000. He obtained his PhD degree in Industrial Engineering from Amirkabir University of Technology, Tehran, Iran in 2006. Currently, he is an Associate Professor in Industrial Management Department at Shahid Beheshti University, Tehran, Iran. His research interests are production planning and scheduling, financial engineering, quality engineering, applied operations research, simulation, and artificial intelligence techniques in the areas of manufacturing systems design.

Behrouz Dorri is an Associate Professor in Industrial Management Department at Shahid Beheshti University, Tehran, Iran. He obtained his BSc degree in Management from Shiraz University, Shiraz, Iran. He also received his MSc and $\mathrm{PhD}$ degrees in Industrial Management from Tarbiat Modares University, Tehran, Iran. His current research interests are decision making principles, change management, and knowledge management. 